\title{
Avaliação e percepção das rotas acessíveis em equipamentos urbanos selecionados no Brasil e Colômbia: estratégias metodológicas
}

\author{
Evaluation and perception of accessible routes in selected urban \\ equipaments in Brazil and Colombia: methodological strategies
}

BEATRIZ HELENA BUENO BRANDÃO

Doutora em Urbanismo, Centro Universitário Inta - UNINTA, biabrandao@unintaflorida.com

LAURA MACHADO DE MELLO BUENO

Doutora em Arquitetura e Urbanismo, POSURB - PUC Campinas, laurab@puc-campinas.edu.br

\section{RESUMO}

Este trabalho tratou das estratégias metodológicas utilizadas para investigar e perceber as rotas acessíveis a partir de equipamentos urbanos selecionados e avaliar as condições de acessibilidade e conectividade desses trajetos. Esses equipamentos urbanos recentes, selecionados em Medellín (Colômbia) e Campinas (Brasil) foram investigados segundo a Avaliação Pós Ocupação, por tratar-se de uma metodologia que analisa os ambientes construídos após a execução e ocupação pela comunidade usuária. Além disso, possibilita a releitura e a reavaliação desses ambientes podendo indicar melhorias a serem implementadas em ações presentes e futuras. A partir dos métodos propostos pela APO, foram adaptados os instrumentos utilizados (fichas de visita de campo, mapas de registro de percursos, mapas de traçado de rotas acessíveis). Foram realizados levantamentos físicos dos equipamentos urbanos selecionados a partir da observação direta em visitas de campo com percursos interno, externo e no entorno; do registro fotográfico no local; da consulta a fotos em livros e sites; consultas aos projetos dos equipamentos investigados e a pessoas significativas, das quais obtivemos depoimentos. A aplicação dessas técnicas possibilitou a elaboração de fichamento dos equipamentos visitados e mapeamento da situação atualizada desses locais, inclusive no registro da mobilidade e da acessibilidade aos usuários. Os equipamentos investigados permitiram compreender a dinâmica própria e diferenciada dos lugares, e perceber que a análise para subsidiar o desenvolvimento de propostas para o aprimoramento de rotas acessíveis deve considerar diferenças físicas e comportamentais observadas.

PALAVRAS-CHAVE: Rotas acessíveis, Equipamentos urbanos, Metodologia, Avaliação Pós Ocupação.

\section{ABSTRACT}

This work dealt with the methodological strategies used to investigate and understand the accessible routes from selected urban equipment and to assess the conditions of accessibility and connectivity of 


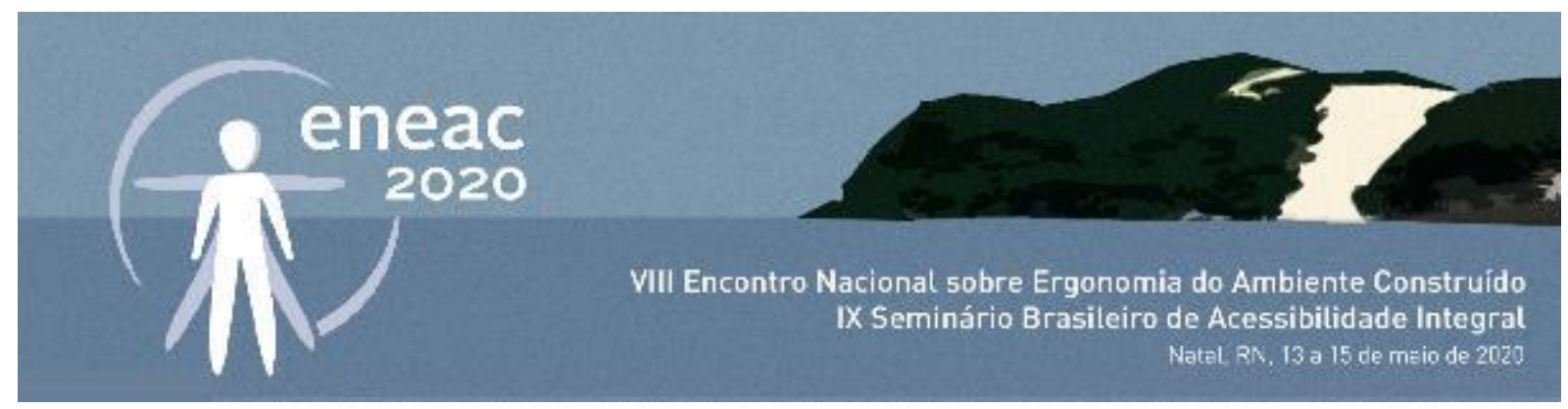

these routes. These recent urban equipment, selected in Medellín (Colombia) and Campinas (Brazil) were investigated according to the Post-Occupancy Evaluation, as it is a methodology that analyzes the environments built after the execution and occupation by the user community. In addition, it allows the reassessment of those environments indicating improvements opportunities that can be implemented in present and future actions. The instruments used (field visit cards, route registration maps, accessible route layout maps) were adapted based on the methods proposed by POE. Physical surveys of the selected urban equipment were carried out based on direct observation in field visits with internal, external and surrounding routes; photographic record on site; books and websites' photos consultation; consulting the investigated equipment projects and significant persons, from whom we obtained testimonials. The application of these techniques allowed us to prepare a file of the equipment visited and map the updated situation of these locations, including the registration of mobility and accessibility to users. The investigated equipment allowed the understanding of each place's proper and differentiated dynamics, and resulted in the perception that the analysis that supports the development of improvement proposals for accessible routes must consider the physical and behavioral differences observed.

KEYWORDS: Accessible routes, Urban equipment, Methodology, Post-Occupancy Evaluation.

\section{INTRODUÇÃO}

O avanço das políticas públicas - com destaque para o protagonismo dos municípios em relação ao desenvolvimento urbano - tem implicações na mobilidade considerada sob a ótica da interação dos deslocamentos e organização da cidade. A esse fato se aliam estudos que apontam para a mobilidade como questão de saúde pública, por suas implicações em causas de mortalidade e acidentes de origem viária, de adoecimento físico pela interação com poluentes e transtornos psicológicos. Está ainda relacionada à sustentabilidade e ao meio ambiente.

Um dos paradigmas atuais da cidade contemporânea brasileira trata da mobilidade das pessoas e da ênfase dada ao transporte ativo, cuja orientação é estimular a utilização dos meios de transporte que dependem da propulsão humana e atende, portanto, aos paradigmas de saúde e sustentabilidade (SEMOB, 2017; SÃO PAULO, 2017). Entendendo, também, que a acessibilidade favorece o transporte ativo, que o transporte a pé é o modo mais utilizado e que é a partir dos ambientes externos que os equipamentos públicos se conectam com o espaço urbano, voltou-se o foco de investigação para as rotas acessíveis externas aos equipamentos urbanos.

O problema de pesquisa envolvendo a complexidade e os conflitos de aplicação na definição de rotas acessíveis indicou a necessidade de proceder a uma revisão bibliográfica sobre acessibilidade. Isso porque a norma NBR 9050/15 da ABNT foi revista e uma nova legislação referente ao tema, a Lei 13.146/15 - Lei Brasileira de Inclusão, foi promulgada em 6 de julho de 2015. Mas o foco principal não estava somente em atualizar os conceitos relacionados à acessibilidade, já conhecidos e utilizados por esta autora em práticas acadêmicas tanto nos cursos de graduação quanto nos projetos de extensão', mas também à aplicabilidade dessas normas e leis no espaço urbano, verificando a complexidade e as contradições dessa ação. 


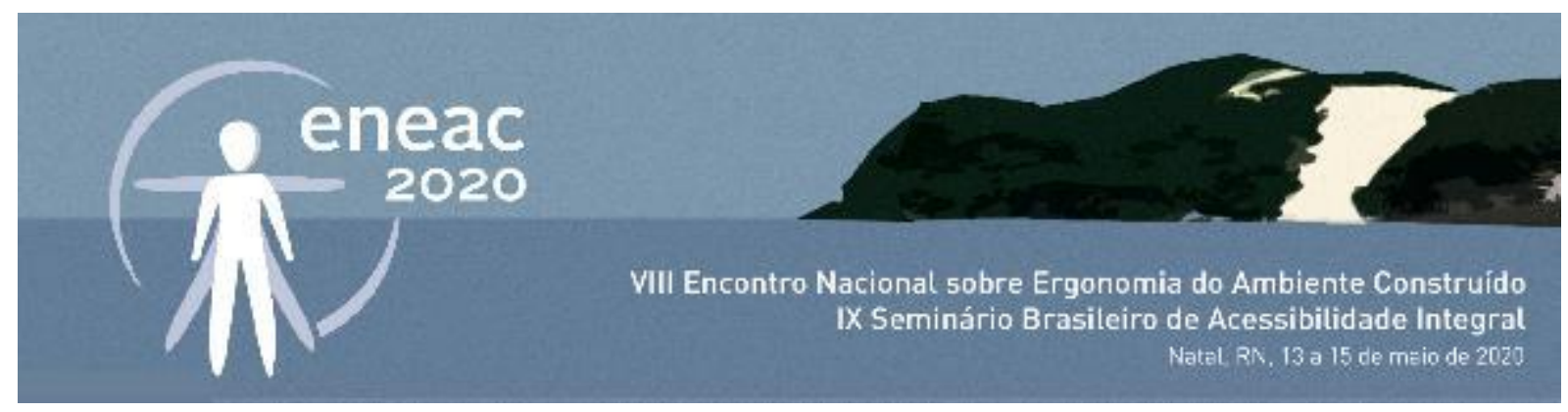

A análise da legislação brasileira nas esferas federal, estadual e municipal, assim como a normativa técnica existente, evidencia a dificuldade dessas bases legais e técnicas em dar conta de universos tão amplos e diversos quanto os espaços das cidades e como há diferenças na sua aplicação em relação aos lugares de implementação, apontando a existência de cidade idealizada versus cidade real.

As leis e normas são generalistas, e os lugares são específicos, seja pela morfologia, seja pelas alterações socioespaciais regionais e intraurbanas que ocorrem na dinâmica de expansão das cidades. Outra questão não menos importante que a análise desse material legal esclarece diz respeito à competência de planejamento e execução das ações e indica a diversidade de atores envolvidos. No caso, por exemplo, das calçadas, a execução compete ao proprietário do lote, mas faz parte da via pública, cuja competência de execução é dos municípios ou dos empreendedores imobiliários.

A avaliação e percepção das rotas acessíveis exigiu a escolha de locais para análise, selecionados nas cidades de Campinas (Brasil) e Medellín (Colômbia). Nestas, foram escolhidos equipamentos públicos de execução recente. A Avaliação Pós-Ocupação (APO) foi a estratégia adotada para a investigação dos locais selecionados por tratar-se de uma metodologia que analisa os ambientes construídos após a execução e ocupação pela comunidade usuária. Além disso, possibilita a releitura e a reavaliação desses ambientes podendo indicar melhorias a serem implementadas em ações presentes e futuras. Essa metodologia é bastante utilizada por profissionais e pesquisadores da área da arquitetura e urbanismo, pois adota procedimentos de pesquisa quantitativos e qualitativos, que se complementam. Uma de suas vantagens é a eficiência na avaliação de espaços destinados ao uso coletivo. A nossa investigação interessou essa abordagem para considerar aspectos de acessibilidade e percepção ambiental.

A partir dos métodos propostos pela APO, foram adaptados os instrumentos utilizados (fichas de visita de campo, mapas de registro de percursos, mapas de traçado de rotas acessíveis). Foram realizados levantamentos físicos dos equipamentos urbanos selecionados a partir da observação direta em visitas de campo com percursos interno, externo e no entorno; do registro fotográfico no local; da consulta a fotos em livros e sites; consultas aos projetos dos equipamentos investigados e a pessoas significativas, das quais obtivemos depoimentos.

A aplicação dessas técnicas possibilitou a elaboração de fichamento dos equipamentos visitados e mapeamento da situação atualizada desses locais, inclusive no registro da mobilidade e da acessibilidade aos usuários. A mescla das sucessivas visitas de campo em horários variados do dia, o contato com usuários e gestores dos equipamentos investigados permitiram compreender a dinâmica própria e diferenciada dos lugares - tanto os centrais quanto os periféricos - e perceber que a análise para subsidiar o desenvolvimento de propostas para o aprimoramento de rotas acessíveis deve considerar diferenças físicas e comportamentais observadas.

\section{ESTRATÉGIAS METODOLÓGICAS ADOTADAS}

\subsection{Seleção dos equipamentos urbanos e rotas selecionados}




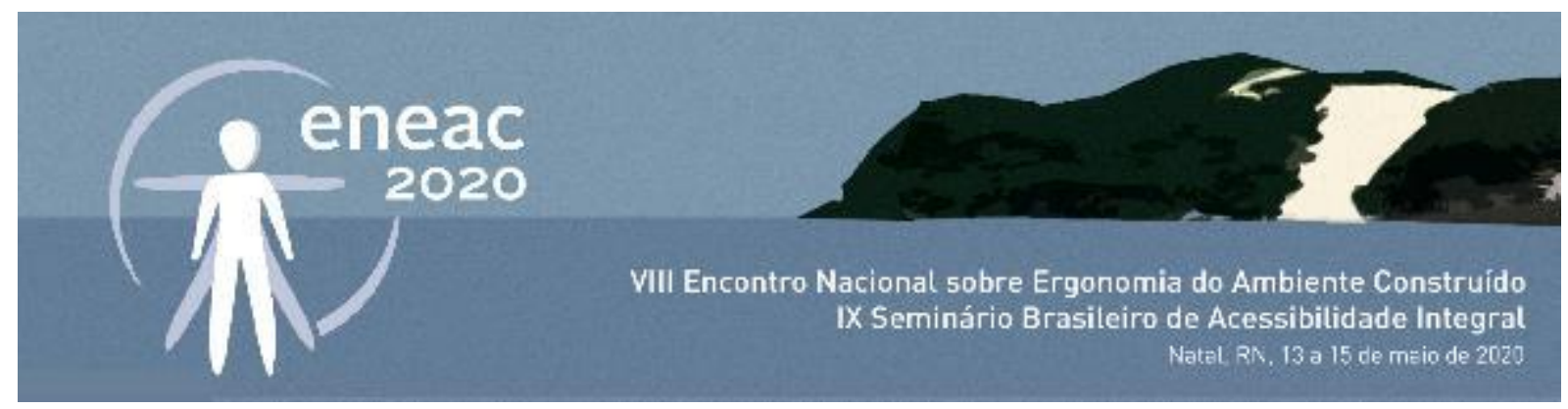

A pesquisa bibliográfica e iconográfica precede o início de qualquer pesquisa, mas, longe de se esgotar nesse momento, trata-se de recurso que se desenvolve paralelamente ao trabalho, em todas as suas etapas. Quanto aos equipamentos urbanos a serem investigados, um dos critérios para seleção foi a atualidade de execução da obra, para que a acessibilidade já fosse um item realizado, ou seja, a partir de 1997 - quando a legislação sobre o tema passou a ser exigida na Colômbia - e em 2000 no Brasil.

Partiu-se da premissa de que os equipamentos fossem públicos, a fim de possibilitar o acesso ao maior número de pessoas e, também, porque a legislação de acessibilidade determina 0 cumprimento de adequação ou adaptação primeiramente nesses lugares. Os equipamentos deveriam estar implantados em áreas urbanizadas das cidades, pois foi a obrigatoriedade de elaboração dos planos de mobilidade inseridos nos Planos Diretores Municipais (PDMs) que fortaleceu a discussão e implementação das ações relacionadas ao direito de ir e vir, à mobilidade das pessoas de maneira mais integrada e sistêmica, e à acessibilidade.

O objeto de estudo definido foram as rotas acessíveis externas em equipamentos públicos de saúde, educação, cultura, lazer, mobilidade e seu impacto na acessibilidade dos usuários. A opção em relação às rotas acessíveis externas baseia-se no fato de que esses trajetos contínuos, como define a norma NBR 9050, fazem parte das condições gerais dos acessos. A partir da publicação de 2015, ela passa a ser, devido à sua relevância, o primeiro item relativo a acessos e circulação.

Apesar de a definição das rotas acessíveis estabelecer que sejam a conexão dos ambientes externos ou internos de espaços e edificações, interessa aqui, especificamente, os espaços externos. Isso porque se entende que eles possibilitam o acesso aos espaços internos e incorporam elementos da circulação urbana, como calçadas, faixas de travessia de pedestres, rampas, escadas e passarelas. Ou seja, de nada adianta que os espaços internos estejam adaptados se os externos não promovem acesso.

Outra aspecto que interessou para esta pesquisa é a relação de conectividade acessível da definição das rotas, isto é, a continuidade de percurso entre duas ou mais rotas acessíveis externas, pois pode colaborar com a tese apresentada de que a execução de rotas acessíveis a partir de equipamentos urbanos pode formar um sistema gradativo de acessibilidade nas cidades. 


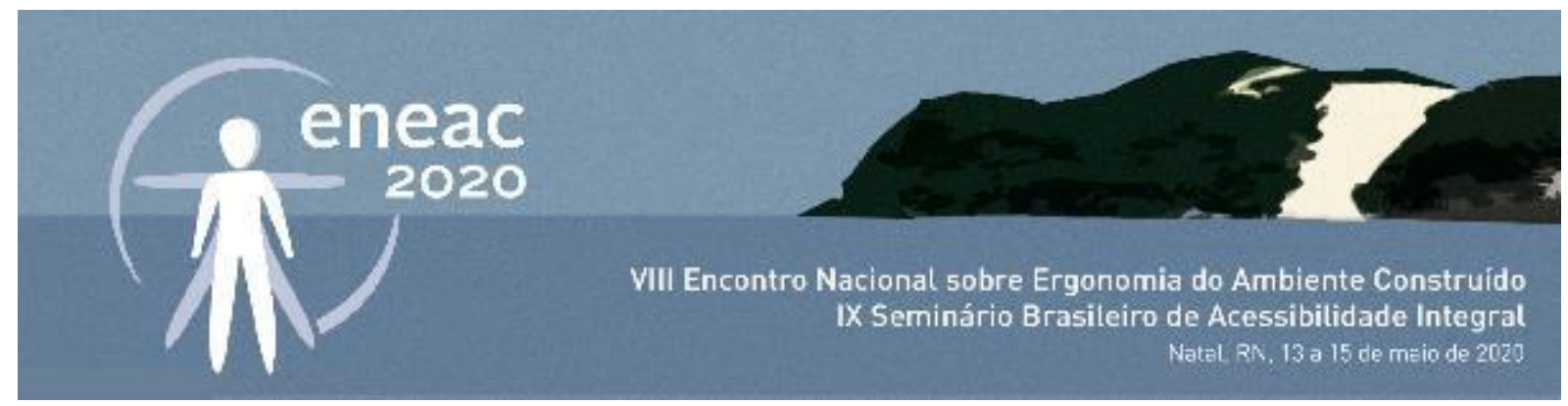

Quadro 1 - Estratégias metodológicas adotadas.

Fonte: Brandão, 2018.

\begin{tabular}{|c|c|c|}
\hline A execução de rotas acessíveis a partir & $\begin{array}{c}\text { TESE } \\
\text { גipamentos urbanos pode formar um sist }\end{array}$ & gradativo de acessibilidade nas cidades. \\
\hline $\begin{array}{l}\text { Estudo de rotas acessíveis externas em } \\
\text { acessibilidade dos usuários. }\end{array}$ & $\begin{array}{c}\text { OBJETO } \\
\text { pamentos públicos de saúde, educação, cul }\end{array}$ & ra, lazer, mobilidade e seu impacto na \\
\hline $\begin{array}{l}\text { É possível identificar o traçado de rotas } \\
\text { acordo com as características dos lugar } \\
\text { incorporados gradativamente, através }\end{array}$ & $\begin{array}{l}\text { HIPÓTESE } \\
\text { íveis externas a partir de equipamentos in } \\
\text { dem necessitar de ajudas técnicas para ter } \\
\text { cessos de interação com os usuários. }\end{array}$ & $\begin{array}{l}\text { antados em áreas urbanizadas, que de } \\
\text { us trajetos completos, e devem ser }\end{array}$ \\
\hline & & PROPOSTAS DE INTERVENÇÃO \\
\hline
\end{tabular}

\subsection{Principais referências utilizadas na seleção dos equipamentos}

Os equipamentos urbanos foram selecionados pelas categorias de educação e lazer, em razão, principalmente, das intervenções arquitetônicas e urbanísticas de Medellín a partir dos Projetos Urbanos Integrais (PUIs). Os equipamentos construídos a partir da premissa dos PUIs são espaços 


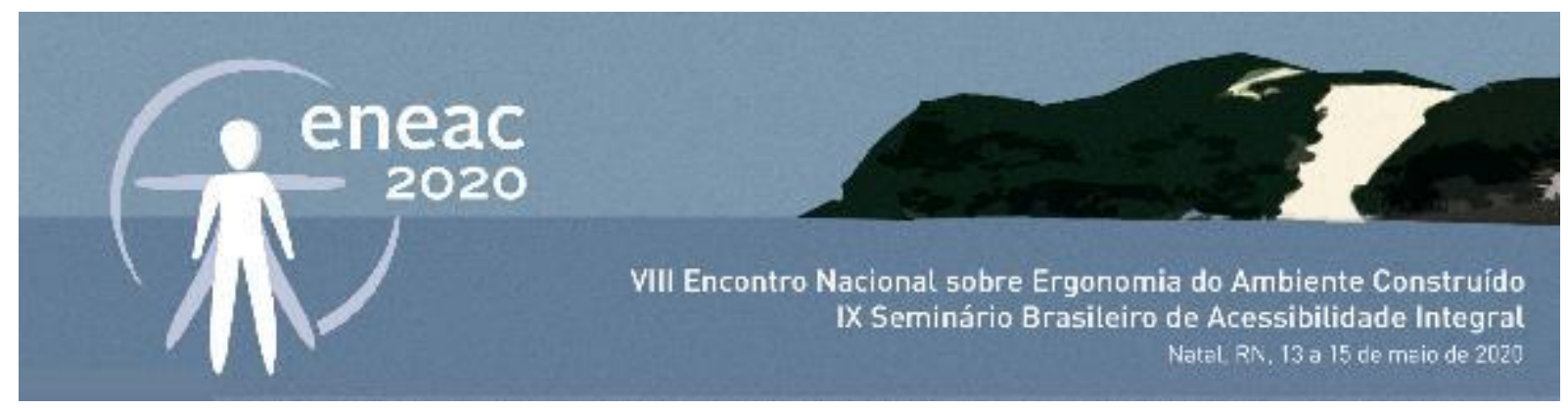

públicos onde a população encontra tanto atividades culturais e educativas quanto de lazer e esportes. A leitura de artigos sobre os modais de transporte em Medellín, especificamente o teleférico, denominado Metroclable (LIMA; ABLA; ANDREOLI, 2014; SANTOS; GONÇALVES, 2014), e sobre as transformações urbanas geradas pela construção dos equipamentos a partir dos PUls (TAMAYO, 2014; ZUQUIM; MAZO; BRANDÃO, 2004) auxiliaram na escolha dos equipamentos urbanos de interesse para a investigação.

Entre a lista elaborada, foram escolhidos dois Parques Biblioteca e, a princípio, a Unidade Desportiva próxima a um deles. Fez-se uma visita exploratória prévia em cada local, a fim de verificar as condições de acessibilidade; feito isso, buscaram-se informações técnicas sobre os equipamentos. As informações coletadas serviram para reafirmar a escolha dos equipamentos e foram anexadas nas fichas elaboradas para as visitas de campo que aconteceram no período de agosto a novembro em Medellín, Colômbiaii.

A escolha do Parque Biblioteca Belén, em Medellín, deu-se em função da sua localização e pelo fato de ser o único dos parques biblioteca cujo projeto não foi realizado pela prefeitura, mas através de doação do governo do Japão, com projeto elaborado pelo arquiteto japonês Hiroshi Naito. A unidade esportiva escolhida próxima a esse equipamento foi a Unidade Desportiva de Belén, que desde 1995 passou a chamar-se Andrés Escobar Saldarriaga, em homenagem póstuma ao jogador de futebol da seleção colombiana. O Parque Biblioteca Espanha foi escolhido por ter sido o primeiro construído dessa série de parques biblioteca.

Um dos jovens da comunidade de Santo Domingo, onde se localiza o Parque Biblioteca Espanha, indicou a Unidade Desportiva Granizal como a mais próxima desse equipamento. Mas a pesquisa pela internet sobre essa Unidade levou à descoberta das Unidades de Vida Articulada (UVAs), equipamentos públicos localizados em determinados bairros da cidade, alguns construídos a partir dos tanques de água da Empresa Pública de Medellín (EPM), destinados às comunidades para prática de atividades esportivas, recreativas, culturais e de participação comunitária. Decidiu-se, então, avaliar também a UVA La Esperanza, próxima da Unidade Esportiva Granizal, e a UVA Novo Amanhecer, próxima do Parque Biblioteca Espanha, que fazem parte dessa tipologia e têm administração da Fundação EPM.

Em Campinas (SP), as escolhas foram, majoritariamente, em equipamentos de educação localizados em bairros da periferia da cidade. Selecionamos a Escola Estadual (EE) Jardim Marisa, a Nave Mãe Governador Leonel Moura Brizola, no Jardim Marisa, e os quatro equipamentos da Vila Esperança: 1) Centro de Artes e Esportes Unificados (CEU) Vila Esperança; 2) Centro de Educação Infantil (CEI) Nave Mãe Eduardo Accioly Campos; 3) CEI Fernando Alpheo Miguel; 4) EE Vila Esperança. As escolhas, em Campinas, se deram em função das características arquitetônicas do EE Jardim Marisa e da proximidade da Nave Mãe com a escola. No caso da Vila Esperança, por ser um dos locais da cidade que possui um equipamento multifuncional como o $\mathrm{CEU}$, pela proximidade entre os quatro equipamentos e pela proximidade dos demais equipamentos, sendo que a Nave Mãe Governador Eduardo Campos e o CEI Fernando Alpheo Miguel estão um em frente ao outro. Também como em Medellín, foram feitas visitas exploratórias aos equipamentos, coleta de informações pela internet sobre os locais de implantação, mobilidade à área e projetos das edificações. 


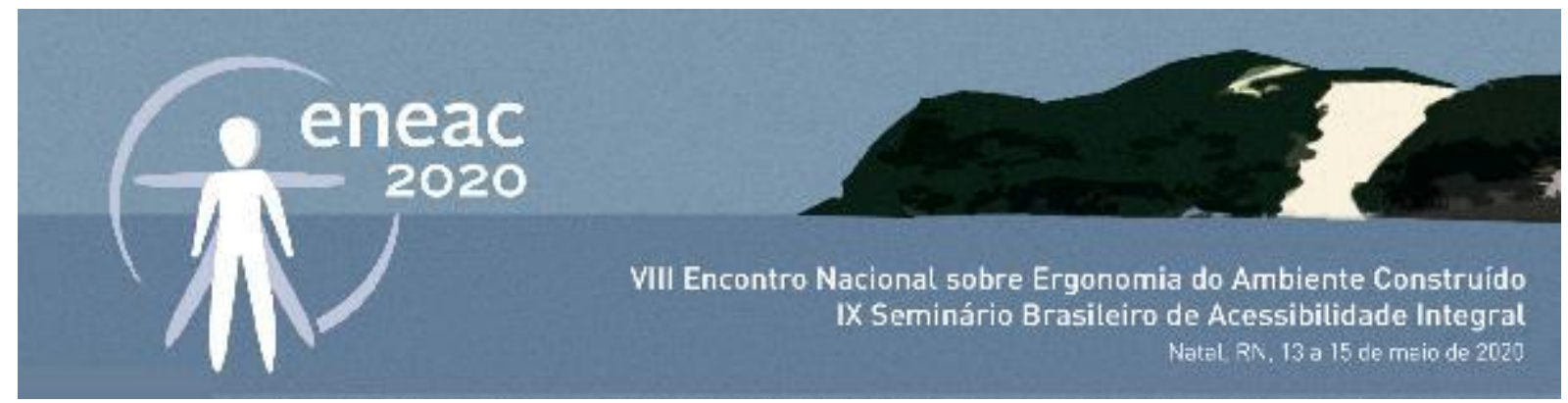

Quadro 2: Indicação das cidades, equipamentos urbanos e percursos investigados

\begin{tabular}{|c|c|c|}
\hline CIDADE & EQUIPAMENTO URBANO & PERCURSO \\
\hline \multirow{4}{*}{ MEDELLíN } & Parque Biblioteca Belén & entorno e interior \\
\cline { 2 - 3 } & Unidade Desportiva Belén & entorno e interior \\
\cline { 2 - 3 } & UVA Novo Amanhecer & entorno e interior \\
\cline { 2 - 3 } & Parque Biblioteca Espanha & entorno \\
\cline { 2 - 3 } & Unidade Desportiva Granizal & entorno e interior \\
\cline { 2 - 3 } & UVA La Esperanza & entorno e interior \\
\hline \multirow{4}{*}{ CAMPINAS } & EE Jardim Marisa & entorno e interior \\
\hline & CEI Nave Mãe Gov. Leonel Brizola & entorno \\
\cline { 2 - 3 } & CEU Vila Esperança & entorno e interior \\
\cline { 2 - 3 } & CEI Nave Mãe Eduardo Campos & entorno e interior \\
\cline { 2 - 3 } & CEI Fernando Alpheo Miguel & entorno \\
\cline { 2 - 3 } & EE Vila Esperança & entorno \\
\hline
\end{tabular}

\subsection{Avaliação Pós-Ocupação e a percepção ambiental considerando aspectos de acessibilidade}

Os aspectos de acessibilidade a serem considerados no caso das rotas acessíveis investigadas dizem respeito às situações externas a partir de equipamentos urbanos inseridos em ambientes característicos e à possível conectividade entre elas. Considerou-se, então, a necessidade de criar um procedimento que respondesse às questões propostas, com um novo olhar, mais direcionado. Foram desenvolvidos procedimentos específicos na pesquisa, a partir de experiências anteriores de projetos de extensão e métodos já existentes, e da aplicação revista do método de avaliação de calçadas Active Design: Shapping the Sidewalk Experience, adaptado pela Organização Cidade Ativa (CIDADE ATIVA, 2015).

Assim, foi desenvolvida uma abordagem multimétodos:

- quantitativos: walkthrough geral para identificação e mapeamento do traçado das rotas acessíveis e dos modais de transporte disponíveis; checklist de acessibilidade das rotas acessíveis e dos modais de transporte disponíveis;

- qualitativos: mapeamento visual dos aspectos físicos, sensoriais, sociais e mapa comportamental para avaliar a apropriação e territorialidade pelos usuários em horários e dias úteis ou não; observação direta dos equipamentos, usos e apropriações pelos usuários.

\subsubsection{Principais referências utilizadas para a Avaliação Pós-Ocupação}

A Avaliação Pós-Ocupação (APO) foi utilizada como metodologia que possibilita a avaliação do desempenho do ambiente construído e do comportamento humano. Neste caso, também pode verificar e diagnosticar as condições de acessibilidade, em especial, para as Pessoas com Deficiência e Pessoas com Mobilidade Reduzida. Entende-se que, assim, o conceito do desenho universal será atendido. Como abordado por Romcy e Santiago, esta metodologia consiste, de maneira geral, na avaliação física do local e na avaliação que os usuários fazem do local a partir de sua utilização (ROMCY; SANTIAGO, 2010). 


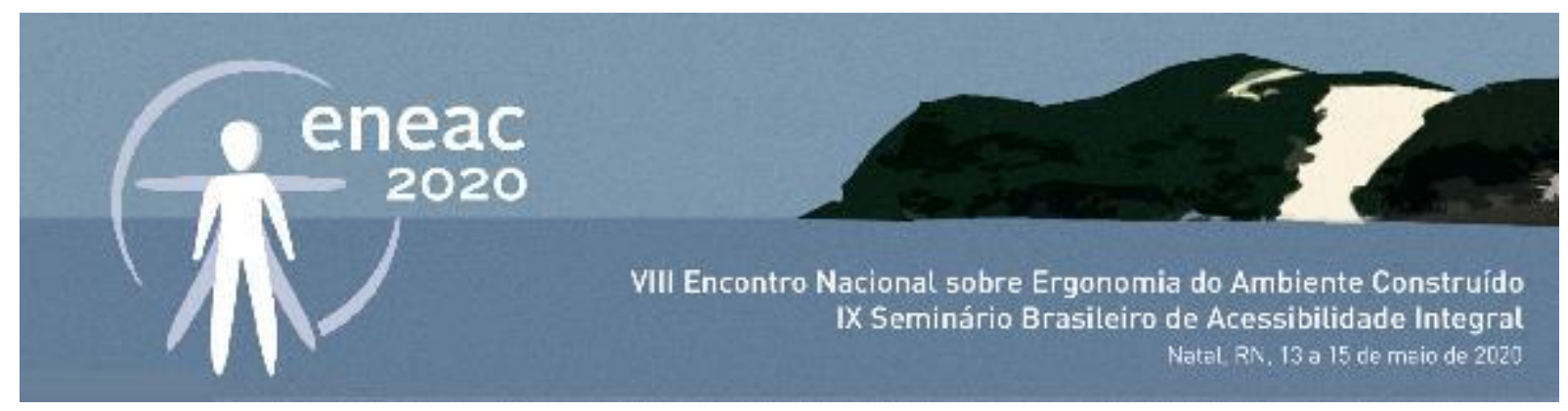

Elaborou-se uma ficha para servir de roteiro de vistoria da acessibilidade das rotas acessíveis. A base para essa elaboração foram roteiros em forma de checklist da Secretaria da Pessoa com Deficiência e Mobilidade Reduzida da Prefeitura da Cidade de São Paulo (SMPED, s.d.), do Conselho Nacional do Ministério Público (CNMP) e os conceitos da Organização Cidade Ativa (CIDADE ATIVA, 2015). Foi feita uma adaptação às necessidades da investigação, uma vez que as três primeiras referências se voltam às edificações, tratando da área externa só enquanto acesso e estacionamento.

O roteiro proposto pela Cidade Ativa é dirigido a avaliar calçadas em relação a seis conceitos que possibilitam tal apreciação: conectividade, acessibilidade, segurança, diversidade, escala do pedestre/complexidade e sustentabilidade/resiliência climática. Ele serviu como referência em alguns itens a serem observados, como os da avaliação de conectividade e acessibilidade, segurança e sustentabilidade/resiliência climática - mas como elementos descritivos e não quantitativos. Isso porque áreas onde a calçada é pensada para o automóvel, e não para o pedestre, a avaliação por contagem de itens ficaria prejudicada. Em relação aos critérios de escala do pedestre/complexidade e diversidade, são mais aplicáveis em áreas de uso misto, onde haja comércio, residências, ou seja, que apresentam maior variedade de elementos a avaliar.

A informação sobre a inserção urbana do equipamento, fundamental no caso dessa investigação, especialmente quanto à morfologia e urbanização do local, é um diferencial da ficha elaborada em relação aos roteiros tomados como exemplos. A ficha criada foi uma adaptação de um modelo de avaliação e possui dois campos específicos para mapas de localização do equipamento no bairro, um de ruas e local para anotação do(s) modo(s) de acesso e outro com a imagem de satélite contendo o uso e ocupação do solo para registro do acesso ao local a partir de pontos de referência. Conta também com uma tabela para preenchimento de itens referentes aos dados de inserção urbana fisiografia e elementos de referência locacional; urbanismo - viário, pontos de ônibus, calçadas, elementos de acessibilidade, ladeiras/escadas/rampas, mobiliário urbano, sinalização vertical e horizontal; uso e ocupação do solo, drenagem, água, esgoto, resíduos sólidos, iluminação pública, arborização pública, vegetação interna. As colunas referentes a esses itens referem-se ao entorno, térreo, execução/alteração e manutenção. A tabela contém, ainda, uma linha inferior para anotação do lugar da visita de campo, mês/ano. A condição de manutenção dos itens verificados foi preenchida a partir de avaliação qualitativa, indicando F (fraco), S (suficiente), B (bom) e Ot (ótimo). Essa ficha, adaptada e simplificada, privilegiando os espaços externos foi mantida para as visitas de campo realizadas no entorno dos equipamentos urbanos selecionados.

Em cada um dos equipamentos foi realizado um walkthrough para verificação da acessibilidade e identificação dos elementos relacionados presentes no entorno, por meio de percursos. Estes foram documentados por registros fotográficos, de maneira a servir para comprobação da realidade observada e como auxílio visual na etapa posterior de sistematização das observações, mapeamento dos aspectos físicos e análise das possibilidades de rotas acessíveis.

Os modais de transporte de acesso aos locais foram identificados, inicialmente, por meio da internet; na maioria das vezes, utilizados para o próprio deslocamento. As visitas de campo realizadas para a investigação das rotas acessíveis se realizaram em mais de um dia, em períodos variados, preferencialmente da manhã e da tarde. Essas oportunidades serviram para observar os usuários do local e utilizar os espaços disponíveis. As visitas foram registradas na ficha previamente elaborada para anotar informações do entorno, registrar o percurso em mapas, identificar as tomadas de fotos, o traçado da rota acessível, os elementos de acessibilidade e mobilidade identificados, e anotar 


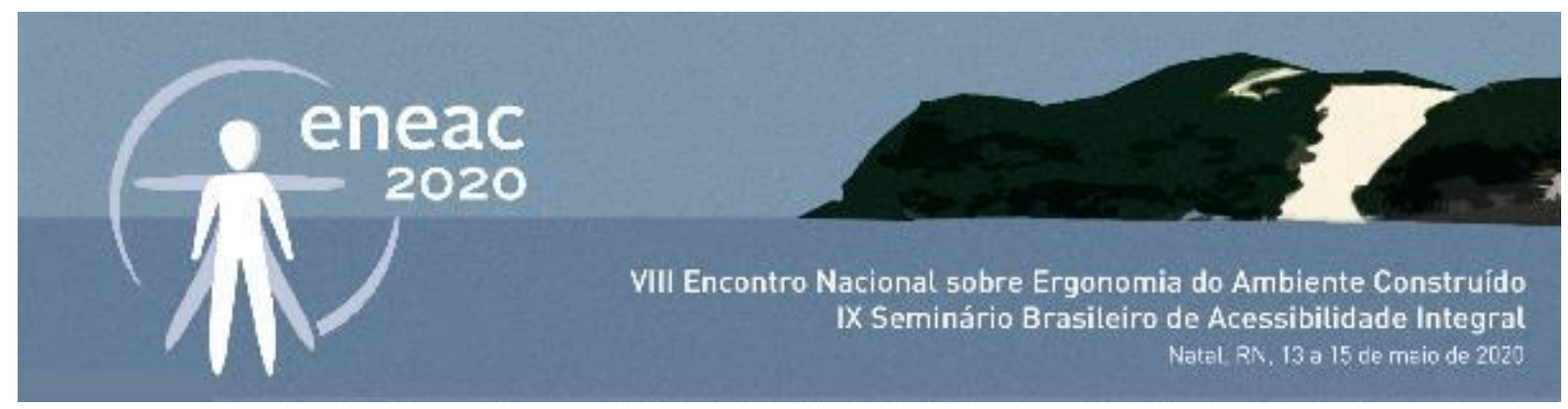

algum pequeno depoimento, se necessário. Os aspectos avaliados podem apresentar situações positivas ou negativas, embasadas na percepção e aferição das situações reais.

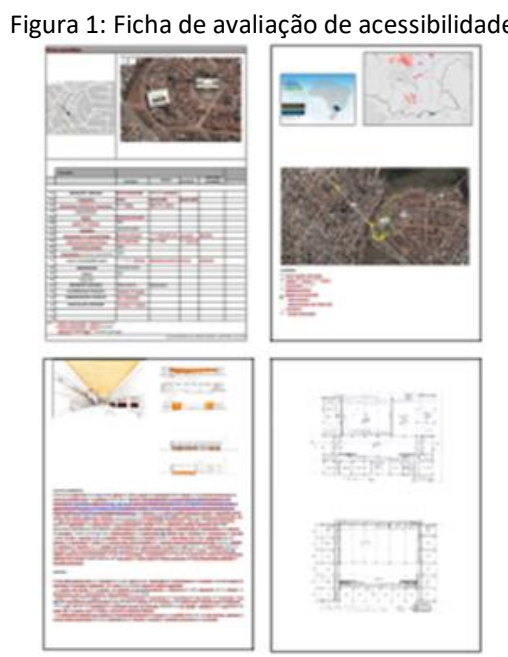

Fonte: Brandão, 2018.

\subsection{Análise de gestão e vivência}

A implementação dos equipamentos urbanos selecionados envolveu ações técnicas, políticas, projetuais e de gestão, cujo conhecimento complementa a análise dos mesmos, envolvendo a compreensão das suas gêneses, execução e manutenção. Isso foi possível a partir da coleta de dados e visita aos equipamentos urbanos e/ou depoimentos dos profissionais projetistas e gestores, para compreender as ações realizadas, a percepção e avaliação dos partidos projetuais e propostas de gestão idealizadas.

\subsubsection{Como foi realizado - principais referências utilizadas}

A cada equipamento urbano correspondeu uma visita exploratória e uma visita técnica de campo para percepção e investigação do local segundo os parâmetros das normas de acessibilidade brasileiras. Outra finalidade dessas visitas reside na possibilidade de vivenciar os locais, compreender melhor os projetos elaborados e publicados, inclusive conhecendo alterações realizadas e/ou ocorridas na pós-ocupação. São os casos do Parque Biblioteca Espanha, em Medellín, fechado porque o revestimento das fachadas dos edifícios estão comprometidos, e do sistema de conforto térmico natural da EE do Jardim Marisa, em Campinas, que está desativado.

Quando possível, houve conversas com usuários do local ou moradores do entorno, colhendo seus depoimentos a fim de confrontá-los com informações coletadas em artigos e sites reconhecidos da área de arquitetura e urbanismo. As conversas com os usuários dos equipamentos ou moradores do entorno foram realizadas durante as visitas técnicas. Algumas, sem agendamento prévio, com 


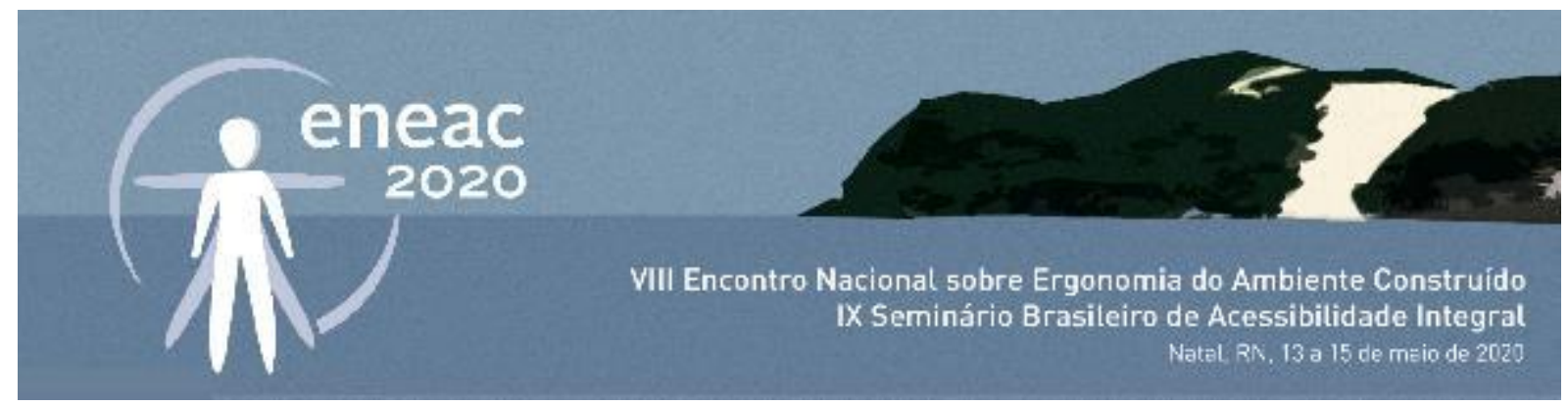

depoimentos espontâneos, gravadas em celular ou registradas por breves anotações e transcritas. Quando necessário, também foram traduzidas.

Os depoimentos dos gestores e profissionais projetistas foram agendados previamente e ocorreram nos locais de trabalho dos profissionais. No contato para agendamento com os gestores e projetistas, o objetivo era explicitado e algumas questões formuladas previamente. Esses depoimentos foram gravados em celular, transcritos e revisados. Os depoimentos dos gestores, acrescidos das leituras efetuadas (ZUQUIM; SÁNCHEZ; MAUTNER, 2017; PÉREZ; AVENDAÑO; MAZO, 2017), foram essenciais para a compreensão da política colombiana, em especial de como foi implementada em Medellín, das transformações legais, urbanísticas e sociais que ocorreram a partir disso, dos programas e atividades dos equipamentos, dos públicos-alvo e frequentadores. Em Campinas, serviram para compreender melhor o funcionamento e atividades dos equipamentos, os públicos-alvo e a distância entre idealizações e realizações, com a ausência de integração e manutenção desses bens públicos.

\subsubsection{Sistematização das informações em mapas; registros das informações coletadas e análises realizadas como subsídio para o desenvolvimento de propostas de intervenção}

As informações técnicas e os registros fotográficos coletados nas visitas de campo e em alguns depoimentos foram organizados e sistematizados em mapas, de modo a possibilitar o aprofundamento no estudo dos equipamentos urbanos e seus entornos. Foram tomados como base mapas do Google Maps e imagens de satélite do mesmo aplicativo. Realizaram-se intervenções indicativas de mobilidade, apontando os modais de deslocamento aos equipamentos analisados, representações dos percursos efetuados no entorno dos equipamentos e indicações nos mapas apontando os locais de tomada dos registros fotográficos, os principais elementos de acessibilidade, de mobiliário urbano e sinalização encontrados.

Figura 2: Sistematização das informações: traçado do percurso (azul) e da rota acessível externa (verde) da Biblioteca Espanha, Medellín

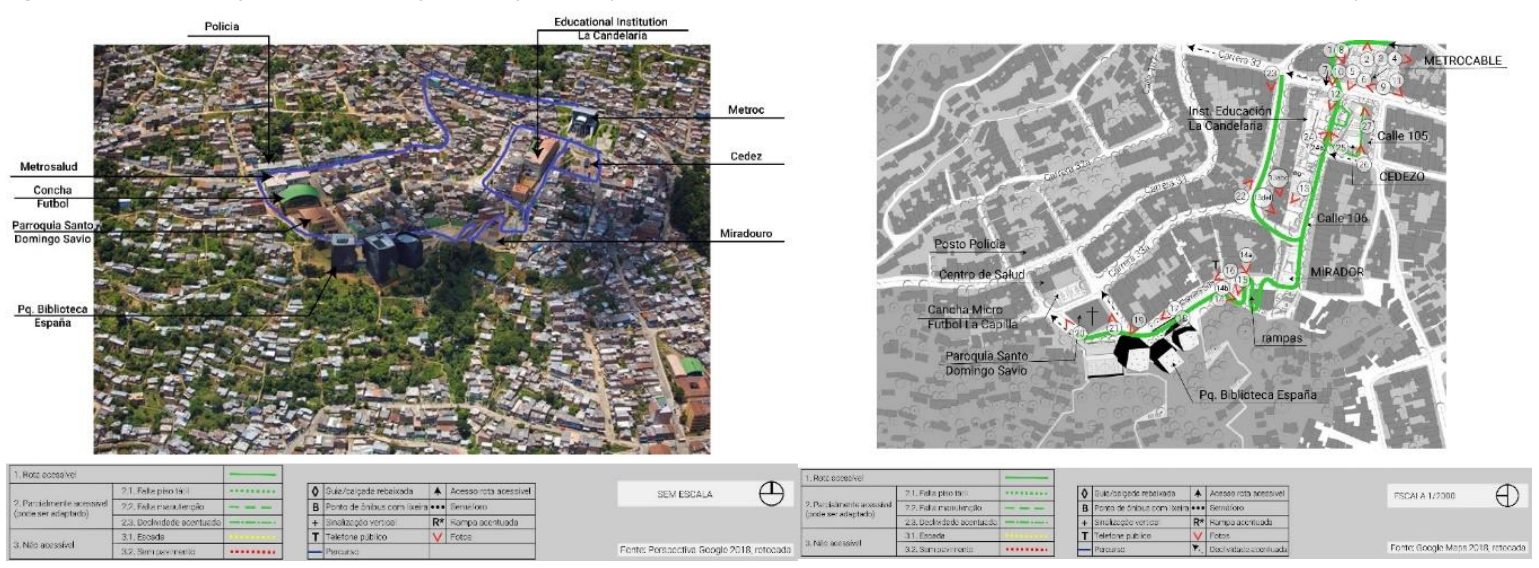

Fonte: Brandão, 2018. 


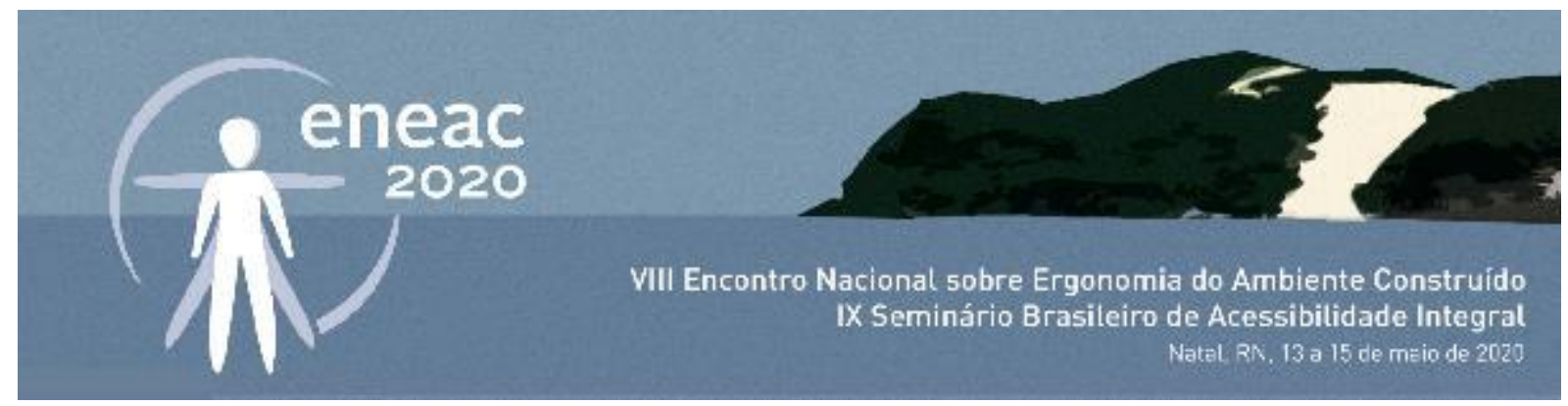

Figura 3: Classificação das rotas acessíveis

CLASSIFICAÇÃO DAS ROTAS ACESSÍVEIS A PARTIR DA INVESTIGAÇÃO DOS EQUIPAMENTOS (como identificado nas legendas)

ROTA ACESSÍVEL;

ROTA PARCIALMENTE ACESSÍVEL: falta piso tátil, manutenção, declividade acentuada;

ROTA NÃO ACESSÍVEL: com escada, sem pavimento.

\begin{tabular}{|c|c|c|c|c|c|c|}
\hline \multicolumn{2}{|l|}{ 1. Rota acessivel } & \multirow{2}{*}{$\overline{ }$} & \multirow[b]{2}{*}{0} & \multirow[b]{2}{*}{ Guia/calçada rebaixada } & \multirow[b]{2}{*}{$\uparrow$} & \multirow[b]{2}{*}{ Acesso rota acessivel } \\
\hline \multirow{3}{*}{$\begin{array}{l}\text { 2. Parcialmente acessivel } \\
\text { (pode ser adaptado) }\end{array}$} & 2.1. Falta piso tátil & & & & & \\
\hline & 2.2. Falta manutenção & --- & B & Ponto de ônibus com lixeira & $\cdots$ & Semáforo \\
\hline & 2.3. Declividade acentuada & -.-.-. & 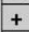 & Sinalização vertical & $\mathrm{R}^{\star}$ & Rampa acentuada \\
\hline \multirow{2}{*}{ 3. Não acessivel } & 3.1. Escada & 020200000 & $T$ & Telefone público & $\mathrm{V}$ & Fotos \\
\hline & 3.2. Sem pavimento & ............ & - & Percurso & & \\
\hline
\end{tabular}

Fonte: Brandão, 2018.

\section{CONSIDERAÇÕES}

A partir desse material, foi possível realizar a análise da acessibilidade, ensaiar o traçado das rotas acessíveis no entorno dos equipamentos selecionados e avaliar suas condições de adaptabilidade e manutenção. O percurso das rotas acessíveis traçadas e a análise da grafia dos mapas serviram como subsídios para o desenvolvimento de propostas de intervenção. Os mapas servem muito bem para a localização dos locais possíveis de intervenção/adaptação, e as fotos servem de suporte para esboçar as propostas numa simulação da realidade.

A análise comparativa da rota acessível externa dos equipamentos demonstra que, embora seja mais fácil a adequação em sítios mais planos do que em regiões de declividade acentuada, isso não é garantia de êxito na conexão e continuidade do trajeto. De maneira geral, a rota acessível está no entorno imediato dos equipamentos analisados, sem se estender em direção às quadras lindeiras, e, via de regra, não configurando conexões acessíveis entre as unidades de um mesmo bairro.

As visitas de campo realizadas nas cidades de Medellín (Colômbia) e Campinas (Brasil) para averiguar as rotas acessíveis dos equipamentos selecionados apontaram que entre dois ou mais equipamentos de um mesmo bairro, setor ou região, a acessibilidade da rota é restrita ao entorno imediato dos mesmos. Entretanto, as adequações poderiam se estender a um raio de ação mais abrangente, de maneira a estabelecer ou complementar uma conexão do tecido urbano entre esses lugares.

Nos casos analisados, como são equipamentos de categorias distintas, cultura/educação e esportes, acredita-se que a conexão entre eles possa trazer benefícios para os usuários, em especial para as pessoas com deficiência e com mobilidade reduzida. Essa percepção levou à realização dos percursos entre os equipamentos e à verificação da existência e possibilidades de uma rota acessível entre eles. 


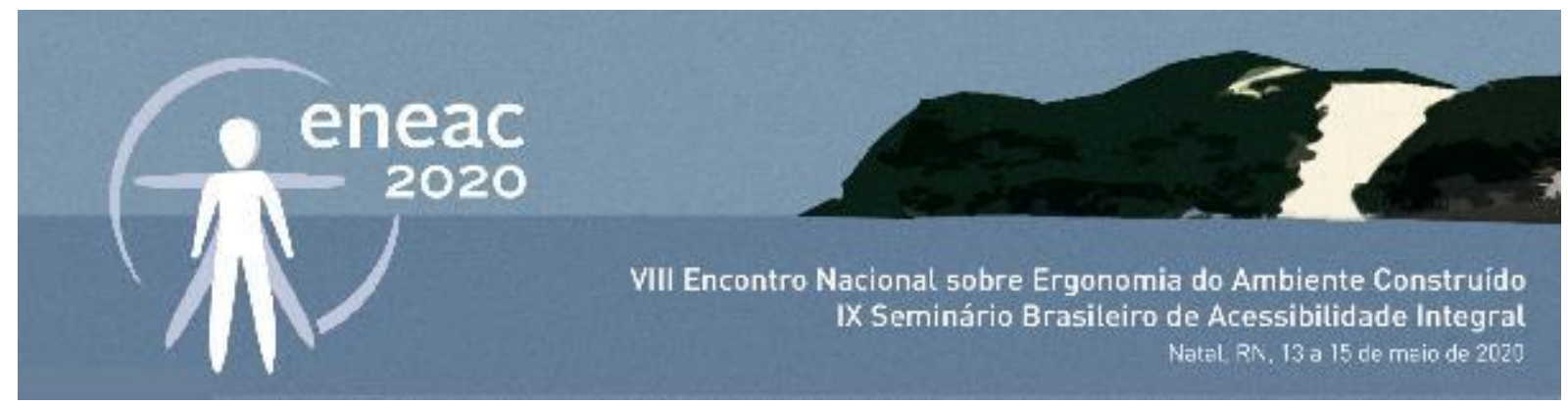

\section{REFERÊNCIAS}

ABNT - Associação Brasileira de Normas Técnicas. NBR 9050/15: Acessibilidade a edificações, mobiliário, espaços e equipamentos urbanos. Rio de Janeiro: ABNT, 2015.

AUTOR. (2018). XXXXXXXXXXXXXX. Tese de Doutorado. Campinas, FAU- PUC-Campinas.

CIDADE ATIVA. Como fazer calçadas ativas? 2015. Disponível em: <http://www.mobilize.org.br/blogs/cidade-ativa/semcategoria/como-fazer-calcadas-ativas/>. Acesso em: ago. 2016.

LIMA, C. H. M.; ABLA, M. M.; ANDREOLI, M. C. Grandes estruturas do PAC em favelas: o caso do teleférico do Alemão. In:ROMCY, N.; SANTIAGO, Z. A avaliação Pós-Ocupação como instrumento na busca da acessibilidade. In: ENCONTRO DE TECNOLOGIA DO AMBIENTE CONSTRUÍDO - ENTAC, 13, Canela, 2010, Anais... Disponível em: <http://www.infohab.org.br/entac2014/2010/arquivos/143.pdf>. Acesso em: 7 out. 2016.

PÉREZ, J.D.L.; AVENDAÑO, D.; MAZO, L.M.S. Entre luchas sociales y avances jurídicos para la garantía de derechos. In: Bairros populares Medellín: favelas São Paulo/organização de Maria de Lourdes Zuquim, Liliana María Sánchez Mazo e colaboração Yvonne Mautner. São Paulo: FAUUSP, 2017. 310 p.: il.

SANTOS, L. B. D.; GONÇALVES, R. S. A questão da mobilidade nos projetos de urbanização: o teleférico como modal de transporte nas favelas. ESCENARIOS: empresa y territorio, vol. 6, n. 8, Medellín, Colombia, julio-diciembre de 2017, p. 15-34.

SÃO PAULO (Município). Lei no 16.673, de 13 de junho de 2017. Institui o Estatuto do Pedestre no Município de São Paulo, e dá outras providências. Secretaria de Documentação. p. 7. Disponível em:

<http://documentacao.camara.sp.gov.br/iah/fulltext/leis/L16673.pdf>. Acesso em: 15 out. 2108.

SEMOB. Secretaria Nacional de Transporte e da Mobilidade Urbana. Ministério das Cidades. Caderno Técnico para Projetos de Mobilidade Urbana: Transporte Ativo. 2016. Disponível em: <http://www.mobilize.org.br/estudos/285/transporteativo--caderno-tecnico-para-projetos-de-mobilidade-urbana.html>. Acesso em: 27 jan. 2017.

. ACESSIBILIDADE - apoio ao Projeto Arquitetônico.

https://www.prefeitura.sp.gov.br/cidade/secretarias/upload/pessoa_com_deficiencia/manual\%20acessibilidade.pdf, acesso em 2017.

SMPED. Secretaria Municipal da Pessoa com Deficiência e Mobilidade Reduzida. ACESSIBILIDADE - Mobilidade Acessível na Cidade de São Paulo. Roteiro Básico para Vistoria. Disponível em: <https://www.prefeitura.sp.gov.br/cidade/secretarias/pessoa_com_deficiencia/noticias/index.php?p=12360>. Acesso em: abr. 2008.

TAMAYO, A. L. G. Parque Explora: intervenção urbana geradora de transformações socioterritoriais no bairro Moravia, Medellín (Colômbia). In: ENANPARQ - ARQUITETURA, CIDADE E PROJETO: UMA CONSTRUÇÃO COLETIVA, 3, 2014. São Paulo, Universidade Presbiteriana Mackenzie; Campinas, PUC-Camp. Anais... p.1-13.

URBFAVELAS - SEMINÁRIO NACIONAL SOBRE URBANIZAÇÃO DE FAVELAS, 1, 2014, São Bernardo do Campo, 2014, Anais... São Paulo. s.n.t., 2014.

ZUQUIM, M. L.; MAZO, L. M. S.; BRANDÃO, A. J. D. N. Intervenções contemporâneas em cidades da América Latina: práticas recentes de intervenção urbana em áreas informais. Brasil - Colômbia. Disponível em:

<http://www.fau.usp.br/pesquisa/napplac/trabalhos/mzuquim/mzuquim_art5.pdf>. 201x. Acesso em: 2017.

; SÁNCHEZ, L. M (Org.); MAUTNER, Yvonne (Col.). Bairros populares Medellín: favelas São Paulo. In: Apresentação. São Paulo: FAUUSP, 2017, 310 p: il.

\footnotetext{
' Os últimos projetos de extensão, realizados na Pontifícia Universidade Católica de Campinas (PUC-Campinas), se deram na Escola Estadual (EE) Oziel Alves Pereira, no Parque Oziel (2014 e 2015) e na lagoa do Jardim São Domingos (2016 e 2017), com os equipamentos de saúde e educação lindeiros, ambos em bairros da periferia de Campinas.
} 


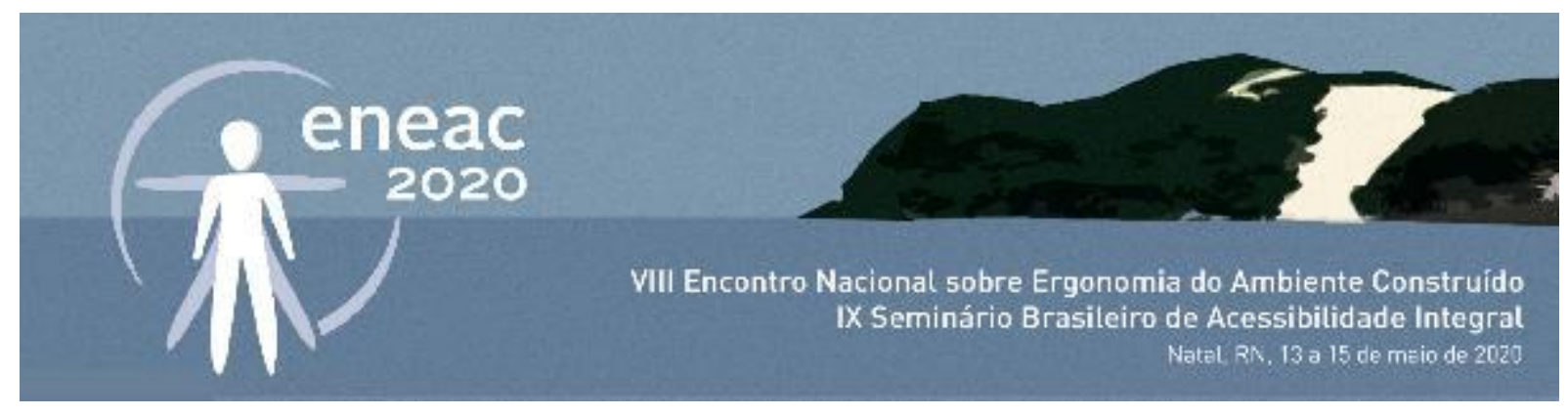

ii Período correspondente à bolsa-sanduíche de Doutorado do Programa de Doutorado Sanduíche no Exterior (PDSE) da Coordenação de Aperfeiçoamento de Pessoal de Nível Superior (Capes). 